\title{
A NEW METHOD FOR THE DETERMINATION OF A CRIMPING DEGREE OF TEXTURED PES FILAMENT YARNS
}

\author{
Jovana Stepanović, Dušan Trajković, Nenad Ćirković, Nataša Radmanovac*
}

(ORIGINAL SCIENTIFIC PAPER)

UDC 677.072.7:677.494.674

Faculty of Technology, University of Niš, Leskovac, Serbia

In the paper, a new method by which it is possible to define the crimping of the textured filament PES yarns is presented. The method is based on the flow analysis of the force - elongation function. POY multifilament polyester yarns, having the fineness of $167 f 36 \times 1$ dtex were analyzed. The texturing of PES multifilament yarns was performed using different first heater temperatures and maintaining the constant temperature of the second heater, then with different texturing speeds at the extension degree of 1.665 and at the ratio of the disc circumferential speed to yarn speed of 2.20. Moreover, the results were compared with the data obtained using standardized crimping testing method.
Keywords: texturing, multifilament, polyester, yarn, crimping

\section{Introduction}

The textured yarn differs from the filament by considerably higher voluminosity and stretchability. The level of stretchability has a big role in creating the appearance and properties of the textured yarn and characteristics of finished products during use.

The voluminosity of the textured yarn results from the waviness of its single threads, often known as crimping. The shape of waves, i.e. crimps, and its characteristics depend on the texturing process and the texturing process parameters. In addition to crimping intensity, often expressed as a crimping degree and the stability ( rigidity ) of crimps, for characterization of the textured yarn crimping, the term characteristic crimping is used.

A special problem in the voluminosity analysis of the textured yarns produced out of partially oriented PES filament yarns ( POY - Partially Oriented Yarns ) is the lack of literature data. Significantly higher number of works deal with the parameter analysis of the textured yarns made of the stretched polyester filament ( FOY - Fully Oriented Yarn ) distinguished by a stable structure [1, 2, 3]. The works studying characteristics of the textured yarns of partially oriented PES filament mainly refer to analyzing the yarns produced in laboratory conditions $[4,5,6]$.

Given that textured filament yarns formed out of POY PES filaments and produced on machines with HT heaters are insufficiently studied, in this work the studies of the impact of some texturing process parameters on crimping of the textured yarns have been presented. Thereby, a new practically applied method for the determination of crimping of textured PES filament yarns based on the results of the analysis of force-elongation function during stretching of the yarns is suggested.

\section{Materials and methods}

The texturing was performed on the machine for frictional stretching texturing with a high temperature heater: FTF15 ( ICBT, France ). Technical-technological characteristics of the machine were: Maximum texturing speed - $1500 \mathrm{~m} / \mathrm{min}$; the length of the first heater $-1.050 \mathrm{~m}$; the length of the second heater - $1.60 \mathrm{~m}$, cooling zone $-1.24 \mathrm{~m}$; friction unit -ICBT unit 1-5-1; working PU discs ( 5 pcs ); C profile.

Textured PES yarn fineness $167 \mathrm{f} 36 \times 1$ dtex, produced under industrial conditions from POY PES multifilament of fineness 278f36x1 dtex, the producer TWD Fibers, Germany.

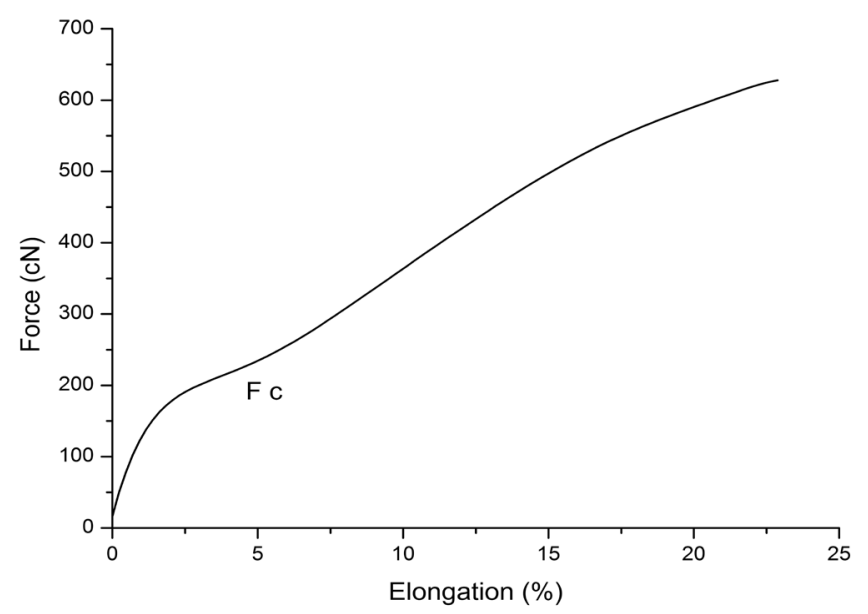

Figure 1. Typical $F-\varepsilon$ curve for filament PES yarn

The analyzed yarns were textured using different tem-

\footnotetext{
*Author address: Nataša Radmanovac, Faculty of Technology, University of Niš,

Bulevar oslobodjenja 124, 16000 Leskovac, Serbia

E-mail: radmanovac@tf.ni.ac.rs,nradmanovac@gmail.com

The manuscript received: March, 13, 2018.

Paper accepted: March, 29, 2018.
} 
peratures of the first heater $\left(350^{\circ} \mathrm{C}, 400{ }^{\circ} \mathrm{C}\right.$ and $450{ }^{\circ} \mathrm{C}$ ) with the constant temperature of the second heater $\left(180^{\circ} \mathrm{C}\right)$, then varying texturing speeds ( $500 \mathrm{~m} / \mathrm{min}$ to $1100 \mathrm{~m} / \mathrm{min}$ ), with a stretching degree of 1.665 and $D / Y$ value of 2.20.

Automatic dynamometer USTER TENSORAPID 4 was used for the determination of mechanical characteristics of the experiment material. The results are shown in the form of typical curves ( Fig.1).

The crimping limit, force and relative elongation values defining the limit were determined analyzing $F(\varepsilon)$ function.

Figure 2 shows the first and the second derivative of $F(\varepsilon)$ function used to determine the crimping limits of analyzed textured PES yarns.
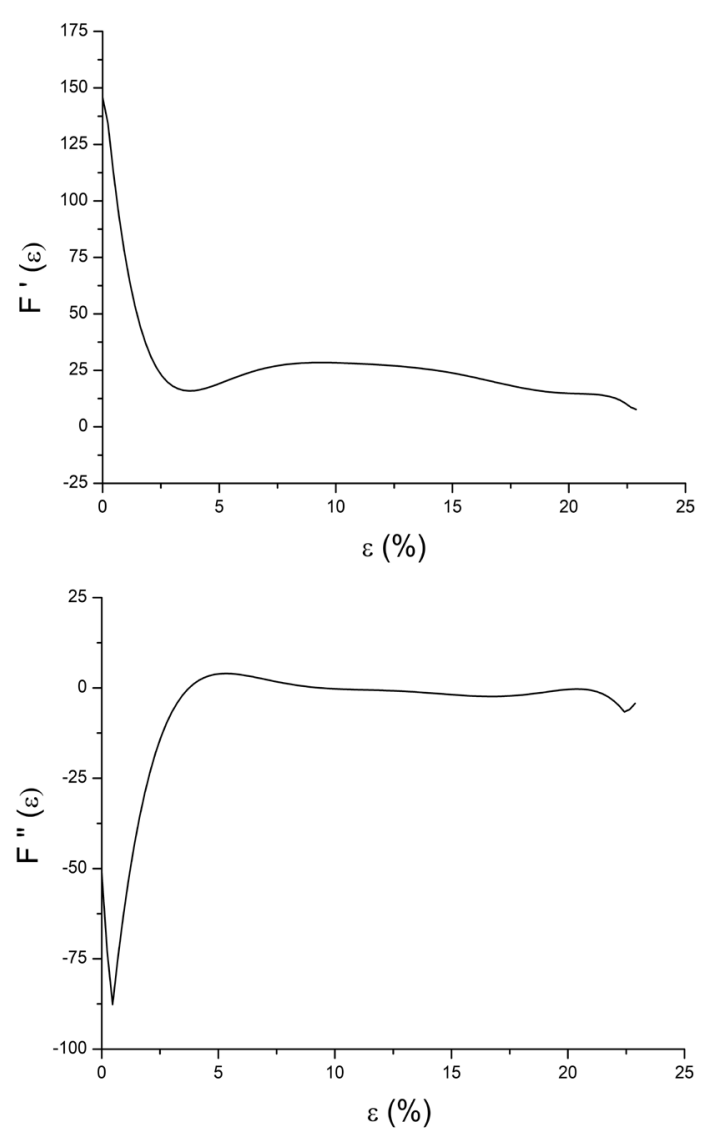

Figure 2. The first $F^{\prime}(\varepsilon)$ and the second $F^{\prime \prime}(\varepsilon)$ derivative of the function

The crimping degree $(C d)$ and characteristic crimping (Cc) were determined according to DIN 53840-1 [7]. The crimping degree and characteristic crimping were calculated from the following equations:

$C_{d}=\frac{l_{0}-l_{1}}{l_{0}} \cdot 100[\%]$
$C_{c}=\frac{l_{0}-l_{2}}{l_{0}} \cdot 100 \quad[\%]$

where: $\mathrm{cN}$,

10 - the length of the yarn hank under the load of 500

$I_{1}$ - the length of the yarn hank under the load of 2,5 $\mathrm{cN}$,

I2 - the length of the yarn hank under the load of 25 $\mathrm{cN}$.

The results obtained for the crimping degree ( a reduced length of the textured filament yarn due to crimping and its crimped structure ) and crimping characteristics ( the elongation of the textured yarn in the range of crimp elasticity ) are presented in Table 1.

\section{Results and discussion}

When the yarn is stretched, first the crimps, created in the texturing process, are stretched and made straight. At the beginning, a higher curve slope can be noticed due to a higher force increase in relation to the elongation of the textured PES yarn. This can be the result of monofilament interlocking, which occurs in the process of false spinning because all monofilaments are not heated uniformly due to their positions in the monofilament yarn and do not receive the same torsion energy. Further stretching releases interlocked monofilaments and up to the point Fc (crimp straitening point ) the decline of the force - elongation function slope is seen. After $F_{C}$ point, the slope increase of force - elongation function is noticeable. At this point, the force required for straightening the crimps, as well as the elongation at this force $(\varepsilon)$ is recorded (Table 1 ). The force $F_{c}$ is determined on the basis of the force-elongation graph at the point of local minimum of the first derivative of the function ( Figure 2 ), i.e. at the point where the second derivative ( Figure 2 ) of the function is equal 0.

Table 1. Texturing parameters and characteristics of textured yarns

\begin{tabular}{ccccccc}
\hline $\begin{array}{c}\text { Sample } \\
\text { No }\end{array}$ & $\begin{array}{c}V \\
\mathrm{~m} / \mathrm{min}\end{array}$ & $\begin{array}{c}\mathrm{T} \\
{ }^{\circ} \mathrm{C}\end{array}$ & $\begin{array}{c}C_{d} \\
\%\end{array}$ & $\begin{array}{c}C_{c} \\
\%\end{array}$ & $\begin{array}{c}F_{c} \\
\mathrm{cN}\end{array}$ & $\begin{array}{c}\mathcal{E}_{c} \\
\%\end{array}$ \\
\hline 1 & 1100 & 350 & 21.800 & 9.093 & 234.00 & 3.11 \\
2 & 1100 & 400 & 24.346 & 10.445 & 223.04 & 3.02 \\
3 & 1100 & 450 & 30.770 & 12.655 & 226.03 & 3.38 \\
4 & 1000 & 350 & 26.009 & 12.552 & 249.14 & 3.42 \\
5 & 1000 & 400 & 30.609 & 15.037 & 233.09 & 3.28 \\
6 & 1000 & 450 & 30.996 & 15.740 & 227.61 & 3.77 \\
7 & 900 & 350 & 27.856 & 13,544 & 222.92 & 3.87 \\
8 & 900 & 400 & 34.723 & 17.732 & 236.41 & 4.06 \\
9 & 900 & 450 & 37.735 & 20.848 & 222.45 & 4.83 \\
10 & 700 & 350 & 22.70 & 10.66 & 212.45 & 4.02 \\
11 & 700 & 400 & 42.11 & 21.54 & 218.33 & 4.53 \\
12 & 700 & 450 & 38.54 & 20.07 & 217.36 & 4.48 \\
13 & 600 & 350 & 22.83 & 11.73 & 211.24 & 3.95 \\
14 & 600 & 400 & 29.30 & 15.36 & 216.11 & 4.13 \\
15 & 600 & 450 & 32.14 & 17.30 & 190.33 & 4.29 \\
16 & 500 & 350 & 28.75 & 14.10 & 214.34 & 4.11 \\
17 & 500 & 400 & 39.44 & 20.42 & 203.13 & 4.54 \\
18 & 500 & 450 & 46.24 & 26.47 & 208.25 & 4.07 \\
\hline
\end{tabular}

Table 1 shows texturing parameters and some characteristics of the analyzed textured PES filament yarn ( $v$ - texturing speed, $T$ - temperature of the first heater, $C d$ - crimping degree, $C_{c}$ - characteristic crimping, $F_{c}$ - the force at the crimping limit, $\varepsilon c$ - elongation at the crimping limit ). 
After $F_{c}$ point, the zone where monofilaments are mainly oriented along the stretching force direction starts, and they are parallel and therefore show a uniform resistance to stretching forces up to the elasticity limit after which permanent deformations of single monofilaments occur.

Figures 3, 4 and 5 show histograms on the basis of which the changes in characteristic crimping [8] ( standardized method) and elongation at the crimping limit ( new method ) can be seen. It can be concluded that the changes are analog. It is mostly observed that the limit speed of $900 \mathrm{~m} / \mathrm{min}$ is the speed up to which textured yarns maintain their voluminosity. At higher speeds, a decline of voluminosity is observed with other constant parameters which affect crimping of filament yarns remaining constant.

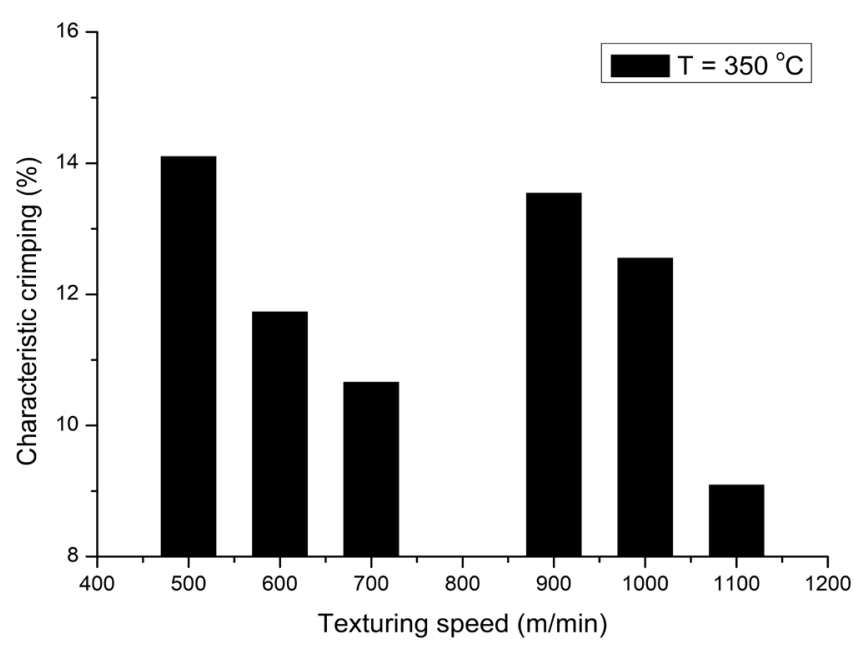

(a)

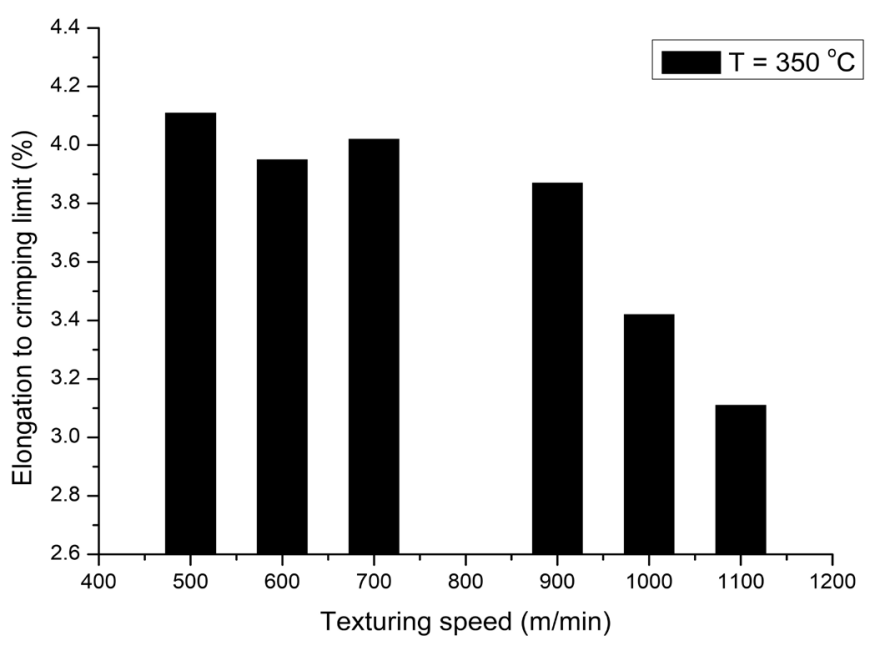

(b)

Figure 3. The effect of the texturing speed on $E k$ and $\varepsilon k$ of textured PES yarns $\left(\mathrm{T}=350{ }^{\circ} \mathrm{C}\right)$; a) Characteristic crimping, b) Elongation to the crimping limit

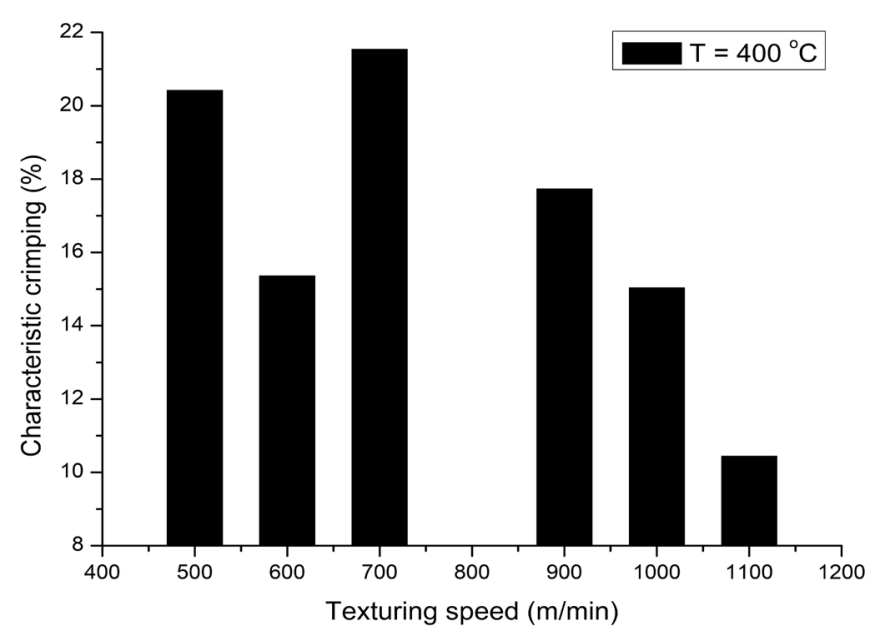

(a)

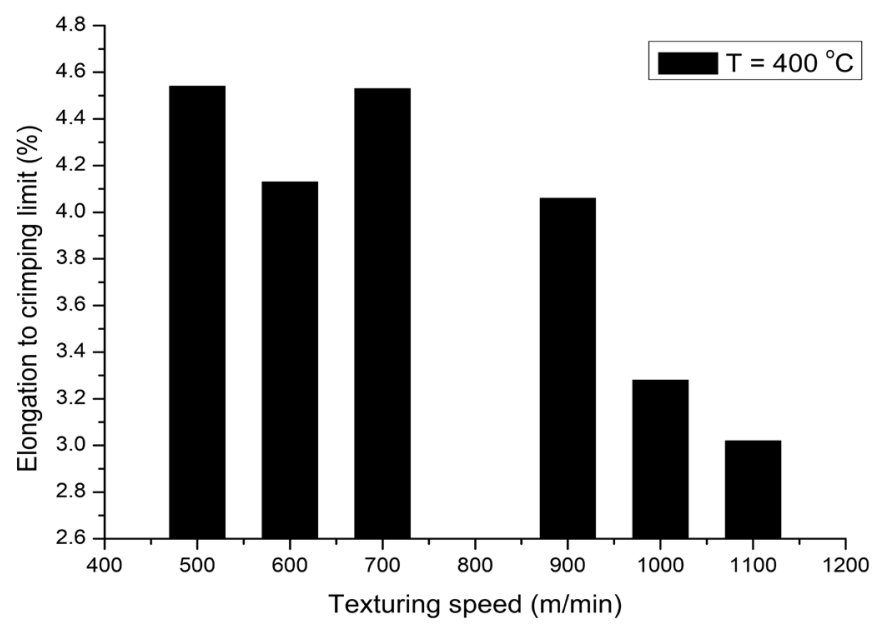

(b)

Figure 4. The effect of the texturing speed on $E \mathrm{k}$ and $\varepsilon \mathrm{k}$ of textured PES yarns $\left(T=400{ }^{\circ} \mathrm{C}\right)$; a) Characteristic crimping, b) Elongation to the crimping limit

POY polyester filament (polyethylene terephtalate ) used in this study is partially oriented with a very low crystallinity degree so that its properties can vary considerably due to structural changes in the texturing process. The most significant parameters of the texturing process are the texturing speed and the heater temperature. Given that these two parameters influence the yarn temperature and its uniform heating in the texturing process, they have a significant impact on the structure of the textured yarn.

In the texturing process by false spinning, POY polyester filament yarns are exposed to the influence of both external stretching and twisting forces and also to internal tension, i.e. contraction due to relaxation processes and increased molecular mobility at a higher temperature. The yarn ability to resist these forces depends on the changes in the yarn temperature determined by the texturing speed and a heater temperature. The influence of these two parameters on the tension within the yarn is opposite, i.e. by increasing the texturing temperature, intermolecular interactions break easier and the mate- 
rial softens resulting in the yarn tension reduction while increasing the texturing speed, the external forces are increased affecting the yarn and the internal stress in the yarn. Therefore, optimal texturing parameters are not easy to define, especially when texturing POY PES multifilament yarns.

Previous conclusions and results obtained show that future investigations should be directed to the analysis of textured yarn properties in the region of elastic deformation, since those results can contribute to link production process parameters with yarn properties and predict their characteristics in further processing.

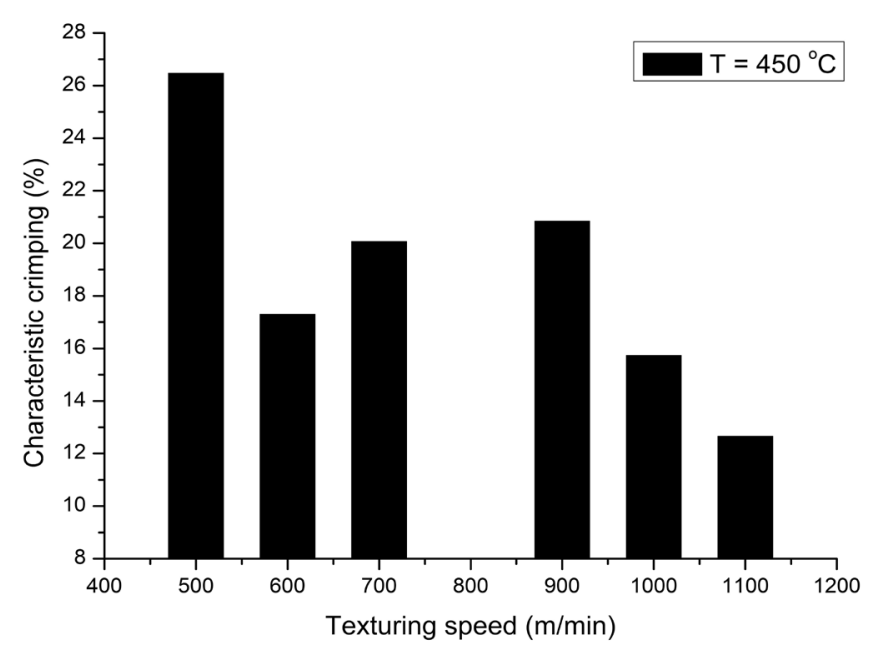

(a)

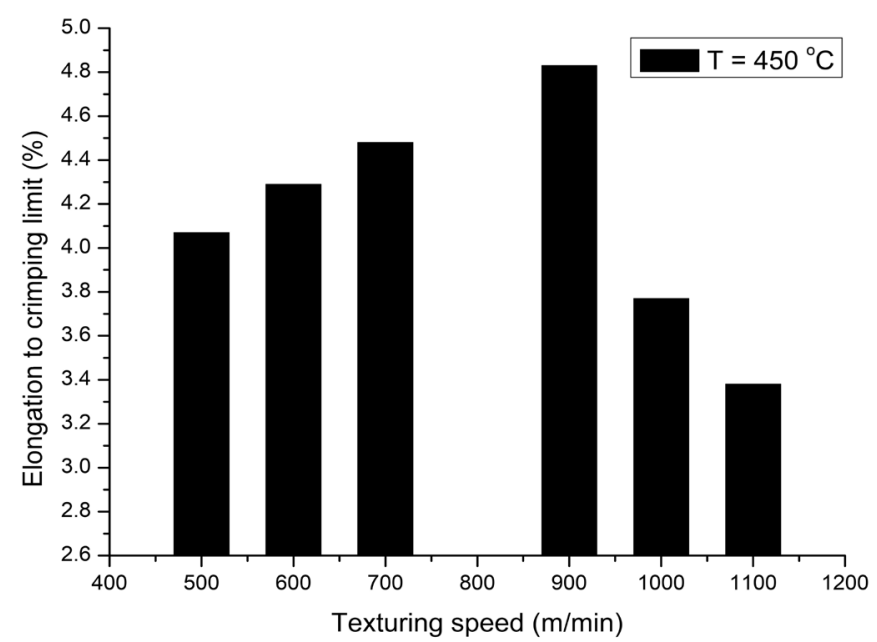

(b)

Figure 5. The effect of the texturing speed on $E k$ and $\varepsilon k$ of textured PES yarns $\left(T=450{ }^{\circ} \mathrm{C}\right)$; a) Characteristic crimping, b) Elongation to the crimping limit

\section{Conclusions}

The texturing is a thermo mechanical process of finishing a synthetic smooth filament by which its appearance and properties are modified producing a specific texture of the newly made yarns.

The quality of the textured yarn is in direct depend- ence of the type and quality of the input POY filament, procedures of its production and the quality of POY wind and its ability to unwind. The texturing process parameters have specific influence on yarn quality parameters, among which the yarn heating temperature, the texturing speed, stretching, false spinning, stabilization, winding the yarn on the spools etc. have a special influence.

The zone of elastic deformation is an insufficiently explored area of the textured PES yarn. The investigation in the zone of elastic deformation is primarily directed to defining the crimping limit and the influence of some process parameters on this property. The results have shown that the limit texturing speed of this yarn is 900 $\mathrm{m} / \mathrm{min}$, from the aspect of preserving higher crimping. Also, the yarns produced using the lowest first heater temperature have lower voluminosity compared to other analyzed samples.

The results of crimping analysis, obtained by a conventional standardized method and by the method based on the analysis of the force-elongation function flow, indicate analog changes of texturing yarn properties under the variable influence of the heater temperature and the texturing speed.

\section{Acknowledgements}

This work is a part of the research project No. TR 34020, financed by the Ministry of Education, Science and Technological Development of the Republic of Serbia.

\section{References}

[1] P. Celik, N. Ozdil, G. Supure; Experimental investigation on the static and dynamic strength of false twist textured polyester yarns, Industria Textila, 62(1) (2011), 38-43.

[2] TN. Shaikh, SS. Bhattacharya; Deriving an empirical formula to determine the optimum level of false-twist in mechanically-crimped textured polyester yarn, Textile Research Journal, 81(9) (2011), 1995-2005.

[3] S.S. Mahish, S.K. Punj, V.K. Kothari; Comfort and Handle Related Properties of P/V Blended Air-jet Textured Yarn Fabrics, Fibers and Polymers, 11(6) (2010), 932-940.

[4] K. Yildirim, S. Altun, Y. Ulcay; Relationship between yarn properties and process parameters in false-twist textured yarn, J. Engineered Fibers and Fabrics, 4(2) (2009), 2632.

[5] MA. Tehran, B. Azimi, MRM. Mojtahedi; Investigating the effect of false twist texturing process on the color coordinates variation of spun-dyed polyester filament yarns, J. Engineered Fibers and Fabrics, 6(4) (2011), 5462.

[6] H. Canbaz Karakaşa, H. Dayıoğlu; Influence of falsetwist texturing parameters on the structural properties of polyester yarn, Indian Journal of Fibre \& Textile Research, 30(1) (2005), 37-41.

[7] DIN 53840-1, Determination of parameters for the crimp of textured filament yarns; filament yarns with a linear density exceeding 500 dtex (1983). 
[8] P. Stojanovic, M. Savic, D. Trajkovic, J. Stepanovic, M. Stamenkovic, M. Kostic; The effect of false-twist texturing parameters on the structure and crimp properties of polyester yarn, Chemical Industry \& Chemical Engineering Quarterly, 23(3) (2017), 411-419.

Izvod

\section{NOVA METODA ZA ODREĐIVANJE KOVRDŽAVOSTI TEKSTURIRANIH PES FILAMENTNIH PREĐA}

Jovana Stepanović, Dušan Trajković, Nenad Ćirković, Nataša Radmanovac

Tehnološki fakultet, Univerzitet u Nišu, Leskovac, Srbija

$U$ radu je prikazana nova metoda kojom može da se definiše kovrdžavost teksturiranih filamentnih PES pređa. Metoda se zasniva na analizi toka funkcije sila - izduženje teksturiranih pređa. Analizirane su POY multifilamentne poliesterske pređe finoće 167f36x1dtex. Teksturiranje PES multifilamentnih pređa vršeno je primenom različitih temperatura prvog grejača uz konstantnu temeperaturu drugog grejača, zatim pri različitim brzinama teksturiranja, uz stepen istezanja 1,665 i odnos periferne brzine diskova i brzine pređe 2,20. Pored toga, rezultati su upoređivani sa podacima dobijenim primenom standardizovane metodom ispitivanja kovrdžavosti.
(ORIGINALNI NAUČNI RAD) UDK 677.072.7:677.494.674

Ključne reči: teksturiranje, multifilament, poliestar, pređa, kovrdžavost 